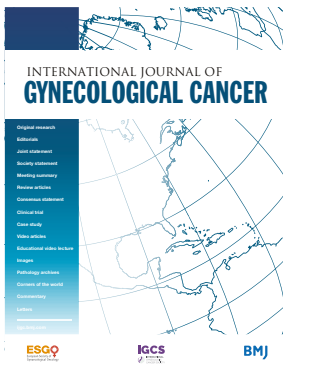

${ }^{1}$ Gynecologic Oncology Department, Cancer Hospital of Barretos, Barretos, São Paulo, Brazil

${ }^{2}$ Pediatric Department, Barretos School of Health Sciences Dr Paulo Prata, Barretos, Brazil

${ }^{3}$ Pediatric Department, Cancer Hospital of Barretos, Barretos, São Paulo, Brazil

\section{Correspondence to} Dr Marcelo Andrade Vieira, Gynecologic Oncology Department, Cancer Hospital of Barretos, Barretos, São Paulo 14784-400, Brazil; mvieiraonco@gmail.com

Accepted 5 January 2021

\title{
Uterine transposition in a pre-pubertal patient
}

\author{
Marcelo Andrade Vieira, ${ }^{1}$ Ana Glenda Santarosa Vieira, ${ }^{2}$ Diego Souza Lima Fonseca, ${ }^{3}$ \\ Gisele Eiras Jorge, ${ }^{3}$ Luis Fernando Lopes, ${ }^{3}$ Rodrigo Chaves Ribeiro ${ }^{3}$
}

In the last few decades, significant treatment advances have changed the landscape of survival in childhood cancer. ${ }^{12}$ However, the burden of treatment-related complications can persist for years. Patients exposed to radiation during childhood are prone to poor reproductive outcomes. ${ }^{3}$ In Video 1 we demonstrate a technique for laparoscopic uterine and adnexal transposition to the upper abdomen in a child. ${ }^{4}$ This is the first report of successful uterine and adnexal transposition and repositioning in a pre-pubertal patient.

A 3-year-old girl was referred to Barretos Children's Cancer Hospital (Barretos, Brazil) in November 2018 with a 7-month history of a palpable mass in the sacral region. Physical examination revealed an intergluteal tumor with unclear boundaries and bilateral inguinal lymphadenopathy. Pelvic magnetic resonance imaging (MRI) indicated the presence of an infiltrating lesion of approximately $10.5 \times 7.5 \times 8 \mathrm{~cm}$ extending from S3 to the coccyx, and bilateral inguinal lymph node enlargement of $2.2 \mathrm{~cm}$. Further examination showed serum levels of lactate dehydrogenase of $1133 \mathrm{U} / \mathrm{L}$ (normal range $313-618 \mathrm{U} / \mathrm{mL}$ ), alpha-fetoprotein $39.7 \mathrm{ng} / \mathrm{mL}$ (normal range $<7 \mathrm{ng} / \mathrm{mL}$ ), and beta-human chorionic gonadotropin $<5 \mathrm{mlU} / \mathrm{mL}$. Excisional biopsy of inguinal lymph nodes showed metastatic yolk sac tumor. After five cycles of chemotherapy with cisplatin, ifosfamide, and etoposide the patient had a partial response and underwent posterior sagittal resection of the residual disease. Histopathologic examination showed a germ-cell tumor (yolk sac tumor) and a positive rectal margin. Radiotherapy was indicated as adjuvant treatment due to margin status.

In an attempt to preserve pelvic reproductive organs before radiotherapy, laparoscopic uterine and adnexal transposition to the upper abdomen was performed. After surgery, the target was delineated according to the tumor volume seen on MRI. She received 5040 cGy in 28 fractions using intensity-modulated radiotherapy with maximum uterine and ovarian doses of 200 and $130 \mathrm{cGy}$, respectively. Ninety days later the uterus and ovaries were repositioned by laparoscopy. Tumor markers at the end of treatment were normalized. After 15 months of follow-up, the pelvic MRI showed no recurrence and tumor markers remained at normal serum levels.

Uterine and adnexal transposition to an upper abdominal region before radiotherapy and subsequent repositioning into the pelvis is feasible with low morbidity in a pre-pubertal oncologic patient and might protect future fertility.

\section{GYNECCOLOGICAL CANCER}

\section{Uterine transposition in a prepubertal oncological patient}

Marcelo de Andrade Vieira, Ana Glenda Santarosa Vieira, Diego Souza de Lima

Fonseca, Gisele Eiras Martins Jorge, Luis Fernando Lopes, Rodrigo Chaves Ribeiro

Check for updates

(C) IGCS and ESGO 2021. No commercial re-use. See rights and permissions. Published by BMJ.

To cite: Vieira MA, Vieira AGS, Fonseca DSL, et al. Int $J$

Gynecol Cancer 2021;31:492493.

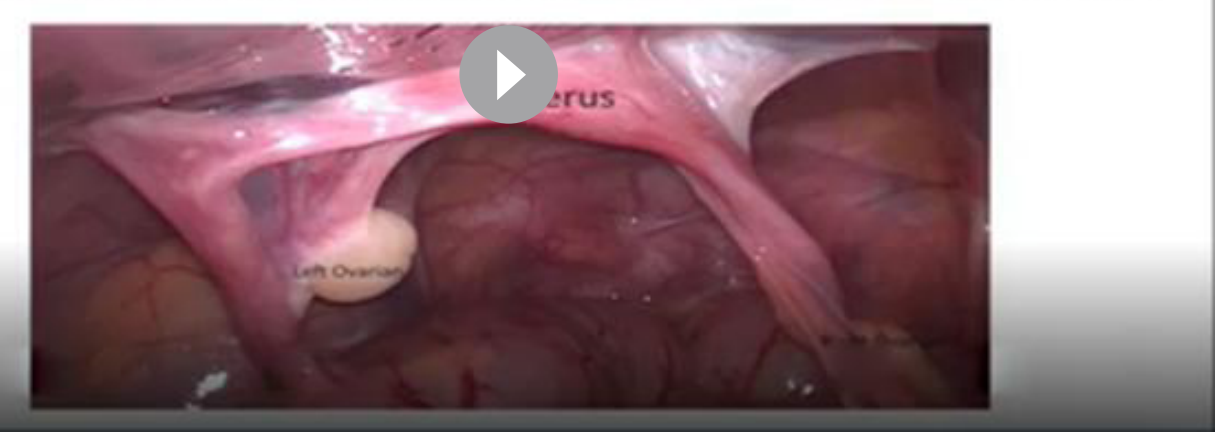

Video 1 Uterine transposition in a pre-pubertal oncologic patient. 
Video article

Contributors MdAV performed the surgery and edited and corrected the final manuscript. AGV edited and corrected the final manuscript. DSLF performed radiotherapy and corrected the final manuscript. GEJ edited and corrected the final manuscript. LFL edited and corrected the final manuscript. RCR performed the surgery and edited and corrected the final manuscript.

Funding The authors have not declared a specific grant for this research from any funding agency in the public, commercial or not-for-profit sectors.

Competing interests None declared.

Patient consent for publication Not required.

Provenance and peer review Not commissioned; externally peer reviewed.
Data availability statement All data relevant to the study are included in the article.

\section{REFERENCES}

1 Ribeiro R, Rebolho JC, Tsumanuma FK, et al. Uterine transposition: technique and a case report. Fertil Steril 2017;108:320-4.

2 Nezhat F, Falik R. Cancer and uterine preservation: a first step toward preserving fertility after pelvic radiation. Fertil Steril 2017;108:240-1.

3 Del Carmen MG. Innovation in fertility-sparing oncology surgery: traversing frontiers. Gynecol Oncol 2018;150:211-2.

4 Baiocchi G, Mantoan H, Chen MJ, et al. Uterine transposition after radical trachelectomy. Gynecol Oncol 2018;150:387-8. 